\title{
Evaluation of Pulmonary Function in Children Undergoing Lung Resection Due to Congenital Lung Malformations
}

\author{
Alican Dincel ${ }^{1}$, Cansu Ylmaz Yegit ${ }^{1}$, Almala Ergenekon ${ }^{1}$, Yasemin Gokdemir ${ }^{1}$, Ela Erdem \\ Eralp $^{1}$, Gursu Kiyan ${ }^{1}$, and Bulent Karadag ${ }^{1}$ \\ ${ }^{1}$ Marmara University Faculty of Medicine
}

June 15,2020

\begin{abstract}
Introduction: Congenital lung malformations (CLM) are rare disorders and surgical intervention is the definitive treatment. Our aim is to evaluate the long term lung function of patients with CLM after surgery compared to healthy children. Methods: 16 children with CLM (M/F: 9/7) and 30 age-matched healthy controls (M/F: 13/17) were included in the study. Demographic data was recorded and both groups were compared by Spirometry and nitrogen based Lung Clearance Index (LCI). Results: Mean age of the patients was $12.0 \pm 5.4$ years old. Mean Forced expiratory volume in 1 second $\left(\mathrm{FEV}_{1}\right)$, Forced vital capacity (FVC), $\mathrm{FEV}_{1} / \mathrm{FVC}$ and Forced expiratory flow between $25 \%$ and $75 \%$ of force expiration $\left(\mathrm{FEF}_{25-75}\right) \%$ pred was, $86.68 \pm 16.65$, $88.00 \pm 14.58,97.44 \pm 9.89$ and $79.00 \pm 26.41$ respectively in patients group. Patients with CLM, had significantly lower values in $\mathrm{FEV}_{1}, \mathrm{FVC}, \mathrm{FEF}_{25-75}$ values than healthy controls (p:0.002, p:0.007, p:0.045). While mean $\mathrm{LCI}_{2,5 \%}$ value in patients' group was $8.33 \pm 1.52$, it was $7.28 \pm 0.80$ in healthy controls (p:0.023). Strong inverse correlation between LCI and FEV $1, \mathrm{FEV}_{1} / \mathrm{FVC}$ was detected in patients' group (p: 0.023 r: -0,581, p: 0.017 r: -0,606 respectively). Conclusion: Current study revieled that patients operated due to CLM have impairment in the pulmonary function compared to healthy children in long term follow-up and LCI may be more accurate detecting airway diseases earlier than spirometry.
\end{abstract}

\section{INTRODUCTION}

Congenital lung malformations (CLM) are rare and a heterogeneus group of disorders including abnormal and dysfunctional pulmonary parenchyma and airways. Congenital lung malformations are a large spectrum of disorders such as congenital pulmonary airway malformation (CPAM), congenital lobar emphysema (CLE), bronchogenic cyst (BC), bronchopulmonary sequestration (BPS $)^{1}$. Surgical resection is the definitive treatment for these lesions with a controversy of elective surgery or conservative treatment in the management of asymptomatic patients and standard surgical treatment method is lobectomy ${ }^{2-4}$. After resection of abnormal congenital lesion, lung volume and function may be expected to improve.

Small peripheral airways are defined as conducting airways and gas exchange bronchioli and alveolar ducts with luminal diameter less than $2 \mathrm{~mm}$. Despite representing large amount of total lung volume, peripheral airways contribute little to overall airway resistance. Therefore peripheral airways can not be evaluated by spirometry which assesses large airways' flow and resistance ${ }^{5}$. Changes and impairment in peripheral small airway structure with pathological processes, affects the distribution of ventilation among different parallel lung units and cause ventilation inhomogeneity ${ }^{6,7}$.

Lung Clearance Index (LCI) is a lung function test derived from multiple breath washout technique. It is defined as dividing cumulative expired volume calculated by assessment of the number of respiratory turnovers required to clear saturated inert gas from the lungs, into functional residual capacity. It exhibits ventilation distribution and reflects peripheral airway status ${ }^{7}$. As LCI is feasible for young children measurements are performed during tidal breathing without require forced expiratory maneuvers ${ }^{8-10}$. 
In early stages of chronic progressive lung diseases without increased general airway resistance, LCI may be much more specific than spirometry to demonstrate periferic airway involvement ${ }^{7,8}$.

Data on long-term lung function in children with postoperative CLMs is rare and in the published articles spirometry is the most preferred method ${ }^{11-13}$. Although surgical resection of the affected part may facilitate the compensatory growth of the remaining lung, it may cause inhomogeneity of ventilation distribution. Depending on this fact, LCI may be more appropriate to evaluate peripherical airway function.

The primary objective of this study is to evaluate the long term lung function of patients who had lobectomy for CLM. As a secondary objective, diagnostic accuracy of LCI and spirometry was compared in patients and healthy controls.

\section{MATERIALS AND METHODS}

This crossectional study was performed at Marmara University School of Medicine, Division of Pediatric Pulmonology, between October 2017 - December 2018.

\section{Sample Selection}

The medical records of forty-four children, surgically treated for CLM between 2006 and 2016 at the Marmara University School of Medicine, Division of Pediatric Surgery, Turkey, were extracted from medical archives. 28 of these patients could not be reached because of having incomplete medical information, changing adresses or phone numbers.

Sixteen patients, who previously had lobectomies with the diagnosis of CLM and 30 age-matched healthy children, as a control group were included to the study. In the both study groups' participants having any chronic systemic and respiratory disease and unable to perform spirometry were not included to the study.

The study was approved by the Research Ethics Committee of Marmara University (approval number: 09.2017.614). Written and verbal consents were obtained from the parents and also over 12 years of age participants' themselves.

\section{Data Collection}

All participants' demographic data, physical examination findings, transcutaneous oxygen saturations (\%), venous blood gases analysis $(\mathrm{Ph}, \mathrm{CO} 2)$ and pulmonary function test (Spirometry, LCI) measurements were recorded. Time of onset of symptoms, localisation of the abnormality, mean age at surgery, pre- and postoperative symptoms and postoperative complications were collected from their medical archives. Respiratory infection symptoms (cough, fever, wheeze, chest pain) were asked as pre- and post-operative symptoms.

Spirometric measurement was performed by using Winspro PRO 2.8 (MIR, Italy). For LCI measurements, Exhalyzer D, EcoMedics AG, Switzerland, (Nitrogen (N2) based), was used. The cut-off value of LCI was defined as the mean LCI value of the control group. Both PFTs were performed in accordance with American Thoracic Society (ATS), European Respiratory Society (ERS) criteria ${ }^{8,10,14}$.

\section{Statistical Analysis}

Continuous variables were presented through means, standard deviations, and medians, whereas categorical variables were presented as proportions. Parameters with normal distribution were compared by independent groups (independent samples) t-test whereas for the parameters without normal distribution Mann Whitney U test was used. Spearman's rho correlation analysis was used to analyze the relationship between two continuous variables that do not distributed normally. Pearson's correlation analysis was used in variables that distributed normally. The $\chi^{2}$ test was used for categorical variables and expressed as observation counts (and percentages). Statistical significance was accepted when two-sided $\mathrm{p}$ value was lower than 0.05. Statistical analysis was performed using the MedCalc Statistical Software version 12.7.7 (MedCalc Software bvba, Ostend, Belgium; http://www.medcalc.org; 2013).

\section{RESULTS}


Sixteen patients with CLM and 30 age-matched control group were included to the study. Of these 16 patients, nine $(56.2 \%)$ were boys and seven $(43.8 \%)$ were girls, mean age was $12.0+5.4$ years. Eleven $(68.75 \%)$ of the patients had congenital pulmonary airway malformation, two patients (12.5\%) had bronchogenic cyst, one patient $(6.25 \%)$ had bronchopulmonary sequestration, one patient $(6.25 \%)$ had congenital lobar emphysema and one patient $(6.25 \%)$ had combined pulmonary airway malformation and sequestration. In the healthy control group, 13 (43,3\%) were boys and 17 (\%56.6) were girls, mean age was 12,5+2.9 years old.

Clinical data, lesion site, age at operation, pre and post-operative symptomatic disease information for patient group were shown in Table-1. Lobectomy was performed in all patients except one. This patient had a BC located in the mediastinum and cystectomy was performed. Six patients having symptoms in the postoperative period were symptomatic before resection as well. All asymptomatic patients remained symptom free after the operation. Some of the patients gave the information of having more than one symptom in the preperative period. In both pre and post-operative period, most frequent finding was recurrent lower respiratory tract infections (LRTI) as shown in Table-1.

At the evaluation visit for both groups, all patients' physical examination findings, transcutaneous $\mathrm{O}_{2}$ saturation values and blood gases analysis $\left(\mathrm{Ph}, \mathrm{CO}_{2}\right)$ were in normal range. Both groups' weight, height and body mass index (BMI) parameters were in normal range according to the WHO references. The PFT for both groups were given in Table-2.

Comparison was performed between the two groups by assessing LCI and spirometry. In LCI measurements 15 of 16 patients having acceptable measurements in the patients group and all participants in the control group (Table-2). Patients with CLM, had significantly lower values in $\mathrm{FEV}_{1}, \mathrm{FVC}, \mathrm{FEF}_{25-75}$ and significantly higher values in LCI compared with the healthy control group.

All patients with normal LCI values (n:4) were also confirmed to be normal by spirometry. On the other hand, we were able to detect impairement in additional 7 patients with LCI measurment in contrast to their normal spirometric results, not reaching to statistical significance $(\mathrm{p}=0.516)$.

There was no correlation between the patients age at surgery and spirometric or LCI values, for Spirometry (P: 0,2 - rho: 0.39), for LCI (p: 0.078 rho: -0.469). Strong inverse correlations between LCI and FEV 1 , $\mathrm{FEV}_{1} / \mathrm{FVC}$ were detected in patients group (p: $0.023 \mathrm{r}$ : $-0,581$, p: $0.017 \mathrm{r}:-0,606$ respectively) (Figure $1 \mathrm{a}$ and $1 \mathrm{~b})$. Also, there were strong inverse correlations between LCI and Spirometric values $\left(\mathrm{FEV}_{1}, \mathrm{FVC}\right.$, $\mathrm{FEV}_{1} / \mathrm{FVC}, \mathrm{PEF}$ ) of all participants' (p: $0.002 \mathrm{r}:-0,449$, p: $0.022 \mathrm{r}:-0,341, \mathrm{p}: 0,009 \mathrm{r}:-0,385, \mathrm{p}: 0,038 \mathrm{r}$ : $-0,311$ respectively).

\section{DISCUSSION}

Current study investigated the role of spirometry and LCI in evaluation of long-term lung function in children with CLM after surgical intervention and revealed that children who underwent surgery for CLM have impairment in lung functions compared to healthy children.

Lung growth and development continues in childhood after birth ${ }^{15,16}$. Also lungs compansate the tissue loss by compensatory growth and remodeling which may result in improvement of clinical condition and respiratory functions after surgical intervention. Most reports showing normal lung functions with spirometry after surgery in the follow-up of CLM patients may suggest this mechanism ${ }^{11,12}$.

In our study, mean spirometric values were within normal range in patients with CLM. Similarly, normal spirometric results was reported by Keijer et al. in 14 post-operative CLM children ${ }^{11}$. Also Beres et al. showed that CLM patients mostly have normal spirometric results in the post-operative period ${ }^{12}$. Even though, lung function test parameters in spirometry were in normal range in both study groups, patients with CLM had significantly lower values than healthy control group. It may be speculated that, CLM patients may have a mild deterioration in lung function in the post-operative period.

Compensatory growth and remodeling after surgical resection of congenital abnormality may cause inhomogeneity in ventilation distribution. In such circumstances, LCI may be more accurate to detect early 
peripheric airway deterioration compared to spirometry. Therefore, LCI was used in addition to spirometry in this study and statistically significant differences were detected between the two groups. LCI assessment results, in long term follow-up, demonstrate that, impairment and incomplete recovery in peripheric small airways occur in CLM patients after surgery.

As mentioned before, LCI is more accurate and sensitive for early detection of lung diseases and evaluating lung function ${ }^{17-19}$. In a study conducted by 43 children with cystic fibrosis (CF) and 28 healthy controls, $23 \%$ of $\mathrm{CF}$ patients had reduced $\mathrm{FEV}_{1}$ and in contrast LCI was found to be abnormal in $\% 63$ of them ${ }^{20}$.

In the current study, although 11 patients out of 15 had abnormal LCI values, only 4 of them had lower spirometric results. So, LCI measurement enable to detect lung function impairement in 7 patients which had normal spirometric results. Also a strong inverse correlation between LCI and spirometry found in our study suggests the usage of LCI in the long-term follow-up of CLM patients

To our knowledge, there is only one previous study comparing LCI with spirometry for the assessment of lung function in post- operative. Mandaliya et al. found abnormal $\mathrm{FEV}_{1} \%$ and LCI values in CLM patients post-operatively compared to healthy controls similiar to our study ${ }^{21}$. In both studies, although $\mathrm{FEV}_{1}$ values were reported to be lower than the controls, they were over the $80 \%$ predicted which is accepted to be the cut-off point for normality. Mandaliya et al. reported lower BMI and height values which may result in a decrease in spirometry and LCI measurements ${ }^{21}$. In contrast to this study, BMI and height of all our patients were in normal range.

In the current study, LCI values of the healthy controls were higher than the previous studies. one of these studies, using the same technique, mean LCI value was found to be as $6.54+0.28$ by Houltz B. et al. in 44 healthy children by nitrogen based $\mathrm{LCI}^{22}$. Mandaliya et. al. reported mean LCI value as $7.3+0.6$ in the control group similiar to our study ${ }^{21}$. Differences in the mean LCI values in different countries requires to be investigated in the further studies. Somatic growth, gender, ethinicity and age can be potential factors explaining these discrepancy

Small sample size may be the major limitation of this study. Therefore, multicenter studies including larger number of patients with CLM are required. Also reference LCI values need to be defined in different groups in larger population studies.

In conclusion, patients operated due to CLM may have impairment in the peripheral airway function in the long term follow-up. Both spirometry and LCI enabled detection of such an impairment in our study. But LCI may be superior to detect changes earlier in the lung function

\section{REFERENCES}

1. Abel RM, Bush A, Chitty LS, Harcourt J, Nicholson AG. Sec 3 Ch 21 Congenital Lung Disease. In: Wilmott RW, Boat TF, Bush A, Chernick V, Deterding RR, Ratjen F, editors. Kendig and Chernick's Disorders of the Respiratory Tract in Children 8th edition 2012, pg. 317-358 .

2. Kim YT, Kim JS, Park JD et al. Treatment of congenital cystic adenomatoid malformation-does resection in the early postnatal period increase surgical risk? Eur J Cardiothorac Surg 2005;27:658661

3. Annunziata F, Bush A, Borgia F, et al. Congenital Lung Malformations: Unresolved Issues and Unanswered Questions. Front Pediatr . 2019;7:239. Published 2019 Jun 13.

4. C. D. Downard et al. , "Treatment of congenital pulmonary airway malformations: a systematic review from the APSA outcomes and evidence based practice committee," Pediatr. Surg. Int. , vol. 33, no. 9, pp. 939-953, 2017.

5. P. D. Robinson, M. D. Goldman, and P. M. Gustafsson, "Inert gas washout: Theoretical background and clinical utility in respiratory disease," Respiration, vol. 78, no. 3, pp. 339-355, 2009.

6. S. I. Fuchs and M. Gappa, "Lung clearance index: Clinical and research applications in children," Paediatr. Respir. Rev. , vol. 12, no. 4, pp. 264-270, 2011. 
7. A. Horsley, "Lung clearance index in the assessment of airways disease," Respir. Med., vol. 103, no. 6, pp. 793-799, 2009.

8. N. Beydon et al. , "An Official American Thoracic Society/European Respiratory Society Statement: Pulmonary function testing in preschool children," Am. J. Respir. Crit. Care Med., vol. 175, no. 12, pp. 1304-1345, 2007.

9. P. Subbarao et al. , "Multiple-breath washout as a lung function test in cystic fibrosis: A cystic fibrosis foundation workshop report," Ann. Am. Thorac. Soc. , vol. 12, no. 6, pp. 932-939, 2015.

10. P. D. Robinson et al. , "Consensus statement for inert gas washout measurement using multiple- and singlebreath tests," Eur. Respir. J., vol. 41, no. 3, pp. 507-522, 2013.

11. R. Keijzer, P. P. L. Chiu, F. Ratjen, and J. C. Langer, "Pulmonary function after early vs late lobectomy during childhood: a preliminary study," J. Pediatr. Surg. , vol. 44, no. 5, pp. 893-895, 2009.

12. A. Beres et al. , "A contemporary evaluation of pulmonary function in children undergoing lung resection in infancy," J. Pediatr. Surg., vol. 46, no. 5, pp. 829-832, 2011.

13. C. Nakajima et al. , "Longitudinal follow-up of pulmonary function after lobectomy in childhood factors affecting lung growth," Pediatr Surg Int. , vol. Jul;13(5-6, pp. 341-345, 1998.

14. M. Miller, J. Hankinson, and V. Brusasco, "ATS/ERS Task Force. Standardisation of spirometry," Eur Respir J., vol. Aug;26(2), pp. 319-338, 2005.

15. D. Mullassery and N. Smith, "Lung development," Semin. Pediatr. Surg. , vol. 24, no. 4, pp. 152-155, 2015.

16. Whitsett JA, Wert SE. Sec1 Ch1 Molecular Determinants of Lung Morphogenesis. In: Wilmott RW, Boat TF, Bush A, Chernick V, Deterding RR, Ratjen F, editors. Kendig and Chernick's Disorders of the Respiratory Tract in Children 8th edition2012,pg. 1-13.

17. Aurora P, Gustafsson P, Bush A, Lindblad A, Oliver C, Wallis CE, et al. Multiple breath inert gas washout as a measure of ventilation distribution in children with cystic fibrosis. Thorax 2004;59(12):1068e73.

18. Aurora P, Bush A, Gustafsson P, Oliver C, Wallis C, Price J, et al. Multiple-breath washout as a marker of lung disease in preschool children with cystic fibrosis. Am J Respir Crit Care Med 2005; $171(3): 249 \mathrm{e} 56$.

19. Horsley AR, Gustafsson PM, Macleod K, Saunders CJ, Greening AP, Porteous D, et al. Lung clearance index is a sensitive, repeatable and practical measure of airways disease in adults with cystic fibrosis. Thorax 2008;63:135e40.

20. P. M. Gustafsson, P. Aurora, and A. Lindblad, "Evaluation of ventilation maldistribution as an early indicator of lung disease in children with cystic fibrosis," Eur. Respir. J. , vol. 22, no. 6, pp. 972-979, 2003.

21. P. H. Mandaliya et al. , "Ventilation inhomogeneities in children with congenital thoracic malformations," BMC Pulm. Med. , vol. 15, no. 1, pp. 1-9, 2015.

22. Birgitta Houltz, Kent Green, Anders Lindbald, Florian Singer, Paul Robinson, Kim Nielsen, Per Gustafsson "Tidal N2 washout ventilation inhomogeneity indices in a reference population aged 7-70 years." Eur. Respir. J., vol. 40, no. Issue Suppl 56, p. P3797, 2012.

\section{Hosted file}

table 1.docx available at https://authorea.com/users/333165/articles/459418-evaluationof-pulmonary-function-in-children-undergoing-lung-resection-due-to-congenital-lungmalformations

\section{Hosted file}

table 2.docx available at https://authorea.com/users/333165/articles/459418-evaluationof-pulmonary-function-in-children-undergoing-lung-resection-due-to-congenital-lungmalformations 


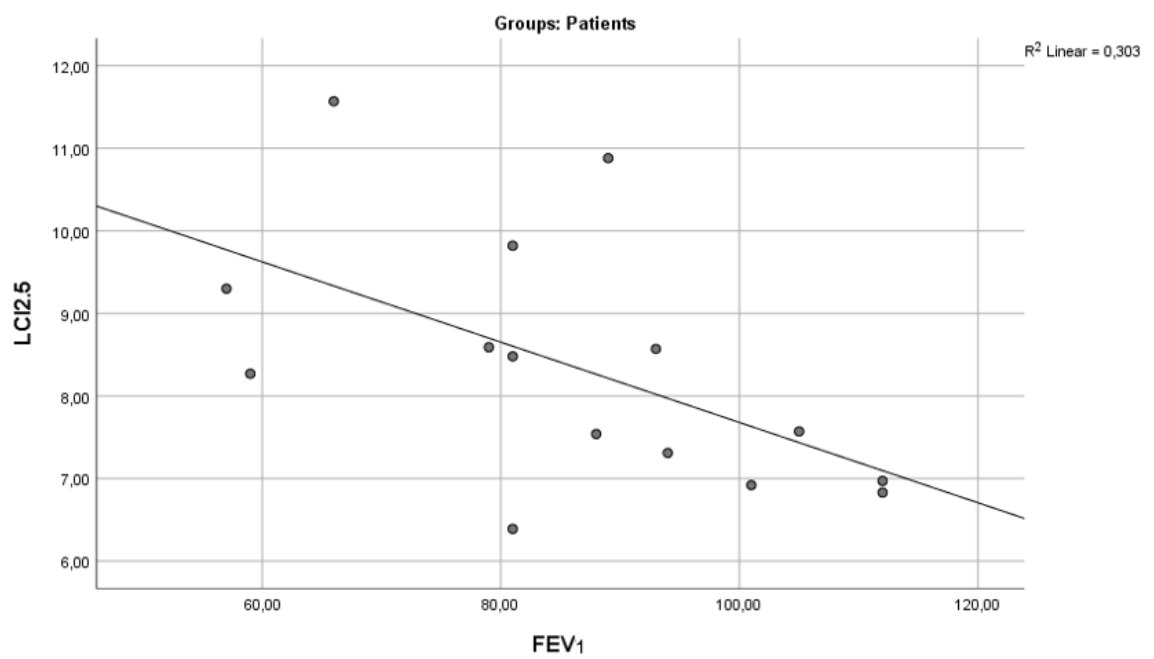

LCI: Lung clearance index, FEV1: Forced expiratory volume in $1 \mathrm{~s}$

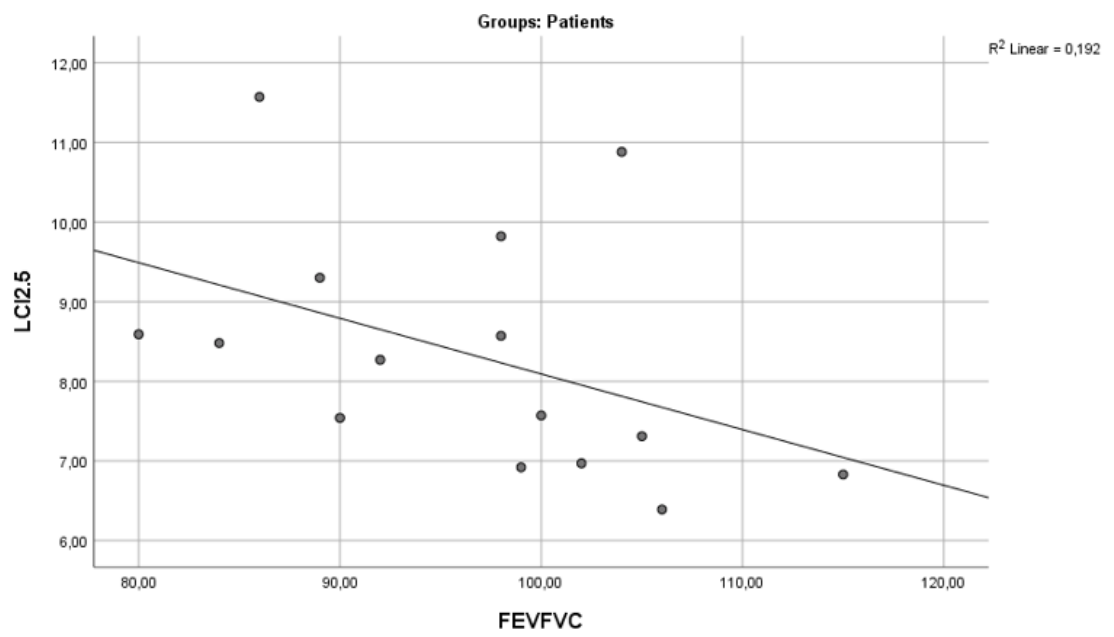

LCI: Lung clearance index, FEV/FVC: Forced expiratory volume divided to Force Vital Capacity 